\title{
Unilateral Versus Bilateral Frontalis Suspension Sling Surgery for Correction of Severe Unilateral Congenital Ptosis.
}

\author{
Jyoti Dhaka', Ashok Kumar Grover ${ }^{2}$ \\ ${ }^{1}$ Senior Resident, SPMC, Bikaner, ${ }^{2}$ Chairman of Department of Ophthalmology, Sir Gangaram Hospital and Vision Eye Centre, New Delhi.
}

\section{Abstract}

Background: To compare the surgical outcome of unilateral silicone sling with bilateral fascia lata frontalis suspension surgery for severe unilateral congenital ptosis. Subjects and Methods: This prospective, interventional and comparative study examined 30 patients of severe unilateral congenital ptosis. 30 patients were divided in to 2 groups, group 1 included 15 patients who underwent unilateral silicone sling frontalis suspension surgery and group 2 included 15 patients who underwent contralateral levator excision with bilateral fascia lata frontalis sling surgery. Results: Mean improvement in MRD1 after surgery in group 1 who underwent unilateral silicone sling surgery was 3.9+1.18 $\mathrm{mm}$ and in group 2 who underwent bilateral fascia lata it was $4.9+0.89 \mathrm{~mm}$ (p value 0.0001 ). Excellent results (difference of lid height <1 $\mathrm{mm}$ ) were seen in $93.3 \%$ patients who underwent bilateral fascia lata frontalis sling while in $73.3 \%$ patients of unilateral silicone sling. All patients who underwent bilateral fascia lata showed excellent lid crease (symmetric without obliteration) and $80 \%$ of the patients who underwent unilateral silicone sling surgery ( $\mathrm{p}$ value 0.032). Conclusion: Functional and cosmetic outcomes regarding MRD1, symmetry of lid height, lid crease were noted better in group 2 patients who underwent contralateral levator excision with bilateral fascia lata frontalis suspension surgery as compared to group 1 patients who underwent unilateral silicone sling surgery.

Keywords: Congenital ptosis, silicone sling, fascia lata, margin to reflex distance, symmetry of lid height.

Corresponding Author: Dr. Ashok Kumar Grover, Chairman of Department of Ophthalmology, Sir Gangaram Hospital and Vision Eye Centre, New Delhi.

Email: drjitendraacharya@yahoo.in

Received: March 2020

Accepted: March 2020

\section{Introduction}

Blepharoptosis or ptosis is defined as an inferior malposition of the upper eyelid margin with respect to the superior corneo-scleral limbus. ${ }^{[1]}$ Congenital ptosis usually presents since birth or occurs within the first year of life. Congenital ptosis may be either unilateral or bilateral. It is seen either in isolation or in conjunction with other ocular or systemic conditions. Acquired ptosis is defined as ptosis presenting after one year of age. Congenital ptosis is mainly due to myogenic dysgenesis of the levator muscle means instead of normal muscle fibres, fibrous and adipose tissues are present in the muscle belly. This leads to a reduction or total absence of the functional muscle, impairing the ability of the levator muscle to contract and elevate the eyelid. Congenital ptosis is reported to unilateral in $75 \%$ of cases the remaining $25 \%$ are bilateral.

Fridenwald and Guyton were the first to describe the frontalis suspension and since then it has evolved in to standard surgical procedure for severe ptosis with poor levator action. ${ }^{[2]}$ Frontalis suspension surgery can be done with several surgical techniques and different sling materials can be used.

The decision for the correction of severe unilateral congenital ptosis is still a dilemma. Some surgeons advocate bilateral levator excision and bilateral frontalis sling surgery in unilateral ptosis, claiming an improved symmetry during downgaze and blinking. On the other hand this approach puts both eyes at risk of lagophthalmos and exposure keratopathy. Some authors advocate excellent results in patients who underwent unilateral frontalis sling. It gives advantage of preserving the healthy eyelid in unilateral ptosis patients. This procedure is better accepted by parents and it reduces surgical risks and operating time.

\section{Subjects and Methods}

A prospective, comparative study was conducted at Vision eye centre, New Delhi from 1st July 2017 to 30th June 2018. Thirty patients, 21 males and 9 females of age ranging from 4 to 28 years having unilateral severe congenital ptosis were included in the study. A detailed history and examination was performed. History included the age of onset of ptosis, its duration, variability of ptosis during the day and excessive fatigue, previous history of trauma or surgery. A complete examination included best corrected visual acuity, cyclorefraction, extra ocular movements, pupillary reactions, corneal sensation, evaluation of lacrimal meniscus was performed. Ptosis examination included vertical palpebral height, upper lid 
margin to reflex distance (MRD1), margin crease distance, levator function, lagophthalmos, jaw winking, bell's phenomenon. Informed consent was taken and patients were divided in to 2 groups on volunteer basis. Group 1 included 15 patients who underwent unilateral silicone sling frontalis suspension surgery and Group 2, 15 patients who underwent contralateral levator excision with bilateral fascia lata frontalis sling.

\section{Surgical techniques:}

Marking: With patient in sitting position, eyelid to be operated was marked as compared to the other eyelid. Desired position of eyelid crease was also marked.

\section{Unilateral silicone sling}

The Pentagon shape was marked over the eye lid. Two incisions were marked just above the lash line each about 3 $\mathrm{mm}$ long. $3 \mathrm{~mm}$ incision was put $5 \mathrm{~mm}$ above the eye brow. The medial and lateral brow incisions were given just above the eyebrow, medial and lateral to their respective lid incisions. One end of the needle was advanced through the supra eyebrow stab incision in the muscle plane. Then it was guided through the lateral eyebrow and eyelid incisions. Once the lateral eyelid incision was reached, the needle was turned horizontally to pass through the medial lid incision and then to nasal eyebrow incision. Finally needle was brought back to the supra eyebrow stab incision. Lid margin height was adjusted according to the amount of correction. The two ends of the silicone band were tied. The single supra eye brow stab incision was closed with 6-0 nylon suture.

Contralateral levator excision and bilateral fascia lata frontalis suspension

\section{Procedure of Fascia lata harvesting}

1 inch long incision was taken at 3 inch above the lateral condyle. The skin incision was deepened through the fat till the glistening fascia is visible. Two linear incisions were given $12 \mathrm{~mm}$ apart on the fascia. The superior end of the fascia was made free by making horizontal cut using a long bladed scissors.

Procedure of levator excision: The levator muscle was approached anteriorly through a skin incision. The orbicularis muscle was dissected and the underlying septum was exposed .The orbital septum was opened to reveal the pre-aponeurotic fat which was dissected from the underlying levator aponeurosis. The medial and lateral horns were freed and the levator was then maximally excised.

\section{Fascia Lata sling suspension}

Four incisions were made $3-4 \mathrm{~mm}$ from the lid border depending on the desired position of the lid fold. The two central incisions were taken on either side of the center of the lid while the other two were at the junction of middle and lateral thirds and middle and medial thirds of the lid.

Two eyebrow incisions were marked at a line perpendicular to the intersection of two incisions made laterally and two incisions made medially while the eyelid was placed in the desired normal position. A third incision was made in the middle of the first two but 3-4 mm higher.

The eyelid incisions were made down to the tarsus and the brow incisions were made up to the frontalis. The two ends of a strip were then passed from the outer eyelid incisions to the outer eyebrow incision using a Wright's fascia lata needle. The needle was passed in the sub-muscular plane from the lateral brow incision to emerge from the lateral incision in the lid. The Wright's needle was again passed from the lateral incision to the second lid incision threaded with fascia and drawn up. The procedure was repeated on the medial side. The fascial strips were pulled up and a double tie was made. The knots were then secured using 5-0 vicryl. One end of fascial strip from each brow incision was pulled through the central brow incision. Knots were tied and buried in the pockets. The brow incisions were closed with 6-0 nylon and the eyelid crease incision by 6-0 nylon. Exclusion criteria included bilateral congenital ptosis, acquired ptosis, blepharophimosis syndrome, history of previous surgery or trauma on eyelids, myasthenia Grevis, poor bell's phenomenon.

\section{Statistical analysis:}

Statistical testing was conducted with statistical package for the social science system version SPSS (version 21). Nominal categorical data between the groups was compared using Fisher's exact test and for intergroup comparison, Mann Whitney $U$ test was used. Level of statistical significance was set at $\mathrm{p}$-value less than 0.05 .

\section{Results}

In both groups results were assessed at the end of 3 months. Ptosis correction was measured by MRD1 and symmetry of lid height.

Excellent symmetry is when lid height difference of $<1 \mathrm{~mm}$, good symmetry is lid height difference 1-2 $\mathrm{mm}$ and poor is when lid height difference $>2 \mathrm{~mm}$.

Lid crease is graded excellent if crease is symmetric without obliteration, good when there is mild obliteration causing asymmetry but acceptable and poor if there is complete obliteration of lid crease. Undercorrection is classified as: Grade 1: 1-2 mm asymmetry of lid height and Grade 2: 2-3 mm asymmetry of lid height.

Mean marginal reflex distance (MRD1) post operatively was found to be $2.9 \pm 1.10 \mathrm{~mm}$ in group 1 and $3.8 \pm 0.52 \mathrm{~mm}$ among group 2 patients. The difference was statistically significant with $\mathrm{p}$ value 0.008 using Mann Whitney $\mathrm{U}$ test.

Table 1: Post op MRD1

\begin{tabular}{|l|l|l|l|}
\hline Groups & Mean & N & Std. Deviation \\
\hline 1 & 2.900 & 15 & 1.1052 \\
\hline 2 & 3.800 & 15 & 0.7270 \\
\hline Total & 3.367 & 30 & 0.9732 \\
\hline P value & $0.008 \mathrm{~S}$ & \multicolumn{3}{|l|}{} \\
\hline
\end{tabular}

Mean improvement of MRD1: Mean difference of pre and post treatment MRD1 value in group 1 was $3.9+1.18 \mathrm{~mm}$ and in group 2 was $4.9+0.89$. When this difference was 2020 
compared using Mann Whitney $\mathrm{U}$ test, it was found to be statistically significant with $\mathrm{p}$ value 0.0001 .

Post-operative symmetry of lid height: Postoperatively among group 1 subjects, excellent results were noted in 11 patients $(73.3 \%)$ and in group 2 it was seen in 14 patients
(93.3\%). This difference was compared using Fisher's test with $p$ value of 0.165 . Good results were seen in 3 patients $(20 \%)$ in group 1 and in 1 patient in group 2 . Poor results were noted in 1 patient in group $1(6.7 \%)$ and nil in group 2.

\begin{tabular}{|c|c|c|c|c|c|c|c|c|c|}
\hline & & \multirow[t]{2}{*}{ Mean } & \multirow[t]{2}{*}{ Std. Deviation } & \multirow[t]{2}{*}{$\begin{array}{l}\text { Std. Error } \\
\text { Mean }\end{array}$} & \multicolumn{2}{|c|}{$\begin{array}{l}\text { 95\% Confidence Interval of the } \\
\text { Difference }\end{array}$} & & & \\
\hline & & & & & Lower & Upper & & & \\
\hline Group 1 & $\begin{array}{l}\text { Difference from } \\
\text { pre to post }\end{array}$ & 3.900 & 1.183 & 0.3055 & -4.555 & -3.244 & -12.766 & 14 & $.0001 \mathrm{~S}$ \\
\hline Group 2 & $\begin{array}{l}\text { Difference from } \\
\text { pre to post }\end{array}$ & 4.966 & 0.895 & 0.2313 & -5.462 & -4.470 & -21.474 & 14 & $.0001 \mathrm{~S}$ \\
\hline
\end{tabular}

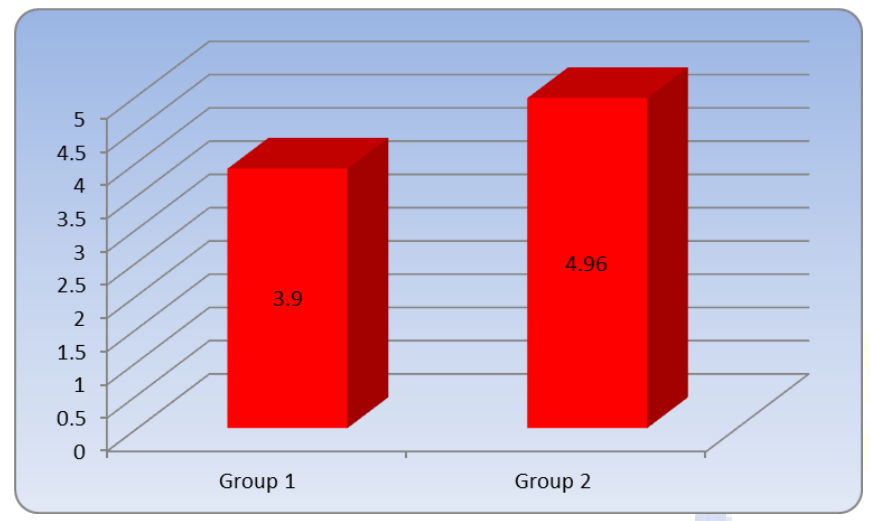

Figure 1: Mean improvement of MRD1

\section{Table 3: Symmetry of lid height}

\begin{tabular}{|l|l|l|l|l|l|l|}
\hline \multicolumn{2}{|c|}{} & Poor & Good & Excellent & Total \\
\hline Groups & \multirow{2}{*}{1} & $\mathrm{~N}$ & 1 & 3 & 11 & 15 \\
\cline { 2 - 7 } & & $\%$ & $6.7 \%$ & $20.0 \%$ & $73.3 \%$ & $100.0 \%$ \\
\cline { 2 - 7 } & 2 & $\mathrm{~N}$ & 0 & 1 & 14 & 15 \\
\cline { 3 - 7 } & & $\%$ & $0.0 \%$ & $6.7 \%$ & $93.3 \%$ & $100.0 \%$ \\
\hline
\end{tabular}

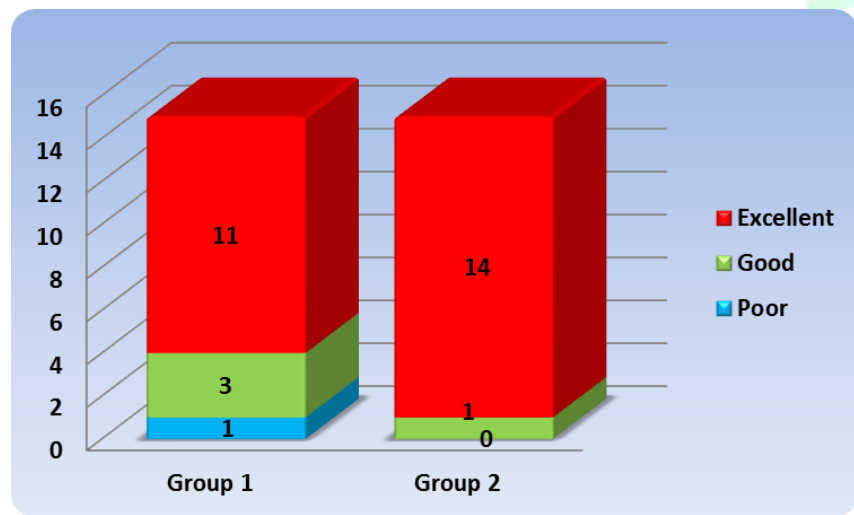

Figure 3: Symmetry of lid height

Post op lid crease: Excellent lid crease was noted in 12 patients $(80 \%)$ in group 1 and in all 30 eyelids of 15 patients in group $2(100 \%)$, it was found to be statistically significantly better among group 2 with $\mathrm{p}$ value of 0.032. Good lid crease was noted among $3(20 \%)$ in group 1.

Post op undercorrection: In 4 patients undercorrection was noted in group 1 and 1 in group 2 .

Grade 1 undercorrection was seen in $3(20 \%)$ patients in group 1 and among 1 patient $(6.7 \%)$ in group 2 .

Grade 2 undercorrection among $1(6.7 \%)$ patient in group 1
$(\mathrm{P}$ value 0.165$)$

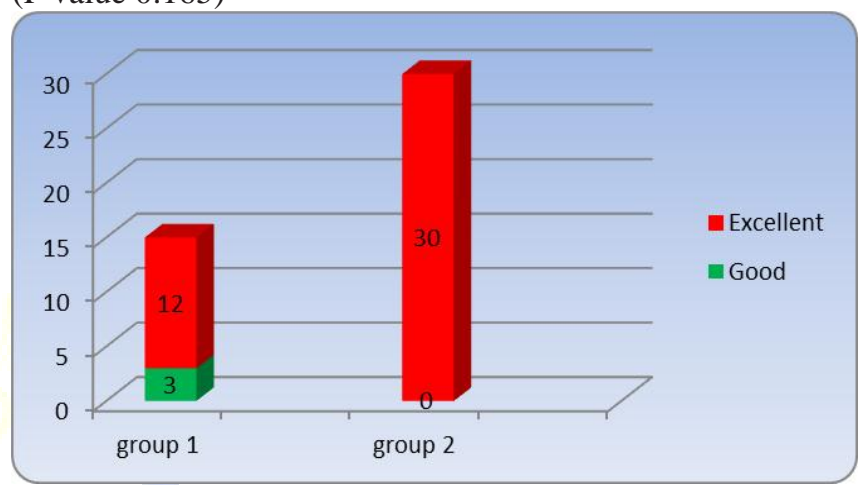

Figure 3: Post op lid crease

\section{Discussion}

Frontalis suspension was first described by Fridenwald and Guyton and since then it has involved in to standard surgical procedure for severe ptosis. ${ }^{[2]}$ Various materials ranging from non absorbable sutures, mersilene mesh, palmaris longus tendon, silicone slings, preserved and autogenous fascia lata have been used as materials for frontalis suspension.

Autogenous fascia lata is considered to be a living suture, which may provide a longer lasting ptosis repair. Importantly, autogenous fascia lata has the advantage of achieving a permanent effect by retaining its cellular viability. Silicone rod sling 3 has been promising in the recent past in being more elastic and adjustable and as it averts the need of an additional surgery to harvest fascia lata. But there is no general agreement on any material to be the best for frontalis suspension.

Symmetry of lids post operatively is both functional and cosmetic outcome measures. An eyelid which looks excellent in the primary position may look bizarre when compared to its fellow eye while looking down or during blinking. Although authors agree on the need for frontalis suspension of the affected eyelid, the management of the contralateral eyelid remains controversial. Three approaches to the contralateral eyelid have been advocated, ${ }^{[4]}$

a) To extirpate the levator muscle so as to create a bilateral ptosis that is then corrected through a bilateral frontalis suspension. 
b) To suspend it from the frontalis muscle without excising the levator muscle,

c) To leave it undisturbed.

Beard, Callahan and Khwarg recommended bilateral frontalis suspension while Carter SR and Kersten recommended unilateral sling surgery. ${ }^{[5,4,10,11]}$

Lee MJ and Oh JY and Hersh and Martin reported better post-operative results in congenital ptosis using silicone sling as compared to preserved fascia lata. ${ }^{[6,7]}$ They reported lower recurrence rate using silicone frontalis sling as compared to preserved fascia lata. However their study was limited to using preserved fascia lata. Preserved fascia lata was shown by Wasserman et al, ${ }^{[4]}$ to be associated with higher ptosis recurrence rates $(51.4 \%)$ compared to autogenous fascia lata (4.2\%).

Autogenous fascia lata grafts are universally recognized as the ideal material for suspension, due to their ability to be fully integrated with excellent take and no rejection issues. They also have a proven track record of good functional and cosmetic outcomes, and their long-term results have also been reported to be superior to any other non autologous material.

Yoon and $1 e^{[8]}$ showed the high functional success rate both in the short and long-term using autogenous fascia lata. Bilgin and Yeniad, ${ }^{[9]}$ noted higher success rate by using autogenous fascia lata even in patients under 3 years of age.

\section{Conclusion}

Blepharoptosis surgery is one of the most common oculoplastic procedure, the main aim of the surgery is to clear the visual axis and the secondary goal is to improve appearance by producing symmetric lid height and crease in the upper lid. The current study found that functional and cosmetic outcomes regarding MRD1, symmetry of lid height, lid crease were excellent in group 2 patients who underwent bilateral fascia lata as compared to group 1 patients who underwent unilateral silicone sling.

\section{References}

1. SooHoo JR, Davies BW, Allard FD, Durairaj VD.Congenital ptosis. Surv Ophthalmol. 2014 Sep-Oct;59(5):483-92.

2. Friedenwald JS, Guyton JS. A simple ptosis operation; utilization of the frontalis by means of a single rhomboid-shaped suture. Am J Ophthalmol. 1948 Apr;31(4):411-4.

3. Morris CL, Buckley EG, Enyedi LB, Stinnett S, Freedman SE. Safety and efficacy of silicone rod frontalis suspension surgery for childhood ptosis repair. J Pediatr Ophthalmol Strabismus. 2008 SepOct; $45(5): 280-8$

4. Kersten RC, Bernardini FP, Khouri L, Moin M, Roumeliotis AA, Kulwin DR. Unilateral frontalis sling for the surgical correction of unilateral poor-function ptosis. Ophthal Plast Reconstr Surg. 2005 Nov;21(6):412-6.

5. Carter SR, Meecham WJ, Seiff SR. Silicone frontalis slings for the correction of blepharoptosis: indications and efficacy. Ophthalmology. 1996 Apr;103(4):623-30.

6. Lee MJ, Oh JY, Choung HK, Kim NJ, Sung MS, Khwarg SI. Frontalis sling operation using silicone rod compared with preserved fascia lata for congenital ptosis a three-year follow-up study. Ophthalmology. 2009 Jan;116(1):123-9.

7. Hersh D, Martin FJ, Rowe N. Comparison of silastic and banked fascia lata in pediatric frontalis suspension. J Pediatr Ophthalmol Strabismus. 2006 Jul-Aug;43(4):212-8.

8. Yoon JS, Lee SY. Long-term functional and cosmetic outcomes after frontalis suspension using autogenous fascia lata for pediatric congenital ptosis. Ophthalmology. 2009 Jul;116(7):1405-14.

9. Bilgin LK, Yeniad B. The Long-Term Results of Frontalis Suspension Using Autogenous Fascia Lata in Children with Congenital Ptosis under 3 Years Old. Plast Surg Int. 2010;2010:609462.

10. Callahan A. Correction of unilateral blepharoptosis with bilateral eyelid suspension. Am J Ophthalmol. 1972; 74:321-6.

11. Khwarg SI, Tarbet KJ, Dortzbach RK, Lucarelli MJ. Management of moderate-to-severe Marcus-Gunn jaw-winking ptosis. Ophthalmology. 1999 Jun;106(6):1191-6.

Copyright: (C) the author(s), 2020. It is an open-access article distributed under the terms of the Creative Commons Attribution License (CC BY 4.0), which permits authors to retain ownership of the copyright for their content, and allow anyone to download, reuse, reprint, modify, distribute and/or copy the content as long as the original authors and source are cited.

How to cite this article: Dhaka J, Grover AK. Unilateral Versus Bilateral Frontalis Suspension Sling Surgery for Correction of Severe Unilateral Congenital Ptosis. Asian J. Med. Res. 2020;9(1):OT05-OT08.

DOI: dx.doi.org/10.47009/ajmr.2020.9.1.OT2

Source of Support: Nil, Conflict of Interest: None declared. 